\title{
Broken Wires, Dropped Devices, Stuck Stents, Lost Coils and rings! Surgery for device related complications of $\mathrm{PCl}$
}

\author{
Jayakrishnan A Gosalakkal', Suraj Chavan \\ From World Society of Cardiothoracic Surgeons 25th Anniversary Congress, Edinburgh \\ Edinburgh, UK. 19-22 September 2015
}

\section{Background/Introduction}

Percutaneous interventions for cardiac disease are on the increase worldwide. Acute complications of interventions include vessel dissection, total occlusion, thrombosis etc. Other than the complications associated with the disease process and the disturbances to the vascular endothelium mechanical complications due to mishandling of or mishaps with the device itself can occur. These complications, though rare do occur and the cardiac surgeon has to deal with them often on an emergency basis.

\section{Aims/Objectives}

To assess the safety and efficacy of emergent surgery in patients who develop device related complications of PCI.

\section{Method}

We present 4 patients with coronary artery disease who had complications during angiogram and attempted angioplasty/stenting. In 1 patients the stent was inappropriately deployed and the patient required urgent surgery for stent retrieval. In one the ring tip of the angiography catheter dislodged in the coronary artery requiring emergency surgery and in a further two patients the guide wire broke in the circulation and had to be retrieved along with coronary artery bypass grafting

In another group of 3 patients there was mishandling of the ASD device requiring urgent retrieval and ASD closure. Devices were" lost" in the LA, in the RA and the other in the Pulmonary artery

In 1 patient undergoing device closure of PDA the device was deployed before proper positioning and was brought down to the femoral artery using a bronchoscopic

Dept. of Cardiothoracic Surgery, Omega Hospital, Mangalore, 575002, India biopsy forceps and then retrieved surgically. In a further patient a PDA coil was "lost' in pulmonary artery, lodging in a small branch. The child underwent surgical closure of PDA. The coil could not be retrieved.

\section{Results}

In conclusion, urgent surgery is often required for device related complications of percutaneous devices. Surgery can be safely undertaken in these patients with gratifying results.

\section{Discussion/Conclusion}

Emergent surgery is lifesaving in patients with device related complications of PCI and can be safely carried out.

Published: 16 December 2015

doi:10.1186/1749-8090-10-S1-A94

Cite this article as: Gosalakkal and Chavan: Broken Wires, Dropped Devices, Stuck Stents, Lost Coils and rings! Surgery for device related complications of PCl. Journal of Cardiothoracic Surgery 2015 10(Suppl 1): A94.

Submit your next manuscript to BioMed Central and take full advantage of:

- Convenient online submission

- Thorough peer review

- No space constraints or color figure charges

- Immediate publication on acceptance

- Inclusion in PubMed, CAS, Scopus and Google Scholar

- Research which is freely available for redistribution 